\title{
PAEDIATRIC ENDOCRINOLOGY - PROSPECTIVES AND NEAR FUTURE
}

\section{Dear Readers,}

It is my greatest pleasure to introduce the papers devoted to Paediatric Endocrinology, coming in the current issue of Scripta Scientifica Medica!

Paediatric Endocrinology is a relatively new but quickly and steadily developing paediatric subspecialty. While it is still unrecognized in some European countries, Paediatric Endocrinology was officially introduced in Bulgaria 20 years ago (in 1995). Even before that, many renowned paediatricians developed both endocrinology and diabetology and put the foundation for further development (professors Zhelev, Damyanova, Stanchev and others). In the 80s Prof. Lilia Peneva was the first Bulgarian paediatrician who officially joined the European Society of Paediatric Endocrinology (ESPE) and paved the way for efficient participation in the life of the biggest professional paediatric endocrine society nowadays. Since then many colleagues joined efforts in improving care for children with short stature, diabetes, rare endocrine and metabolic diseases and scientific potential grew in parallel. In 2010 the Varna Paediatric Endocrine Society (VAPES) was registered, and a year later - the Bulgarian National Society of Paediatric Endocrinology (BNSDE). Many causes have been raised and many problems solved, especially in day care. Both BNSPE and VAPES endorse the ESPE Training Syllabus (https://www.eurospe.org/education/education_training.html), and the quality and knowledge of trainees is improving constantly. This brings new successful researchers in the field, and gradually increases the number of publications in respected international journals. A good appraisal of the merit of the discipline's development is the attraction of World renowned speakers to the annual meetings of both VAPES (www.vapesbg.org) and BNSPE (www.bnsde.org).

In this issue the first 4 papers from a series will appear. Prof. Stenvert Drop and co-authors are presenting an interesting analysis of the activity and achievements of a group of Paediatric Endocrinologists (fellows, junior and senior specialists/consultants) during one of the postgraduate educational initiatives of VAPES. ESPE e-learning portal is a large and important initiative of ESPE (www.espeelearning.org). Dr Drop as its conceptual father and Director has participated in every step of its development and is currently doing his best to popularize it in different parts of the world, as well as make it accessible in other languages. Having Prof. Drop's paper in our journal is not only a pleasure but also an honor. The paper does not only show the achievements of the modern technology that broaden the horizon of expert learning, but also points the pit-falls and directions for further improvement. The possibilities for self- and educator monitoring of the learning process makes it more effective and beneficial.

In the last few years the field of the child bone health started to develop systematically. Not only diagnosis was improved, but also previously unavailable types of treatment and management were introduced. Dr Vesselin Boyadzhiev and co-authors describe a patient who mixes two rare entities isolated growth hormone deficiency and multiple enchondromatosis - Ollier disease, that to our best knowledge have not been described together yet. This case presentation reminds the audience that of-

Scripta Scientifica Medica, vol. 46, No 3, 2014, pp. 7-8

Copyright $\odot$ Medical University of Varna 
ten time is needed for a certain entity to become visible, and that follow-up and regular assessment of patients is a reliable tool for the improvement of the diagnostic skills of the Paediatric Endocrinologists. Important questions about re-assessment and further growth hormone treatment are also raised.

Paediatric Endocrinology has been facing the problems of childhood rare diseases very actively in the last decades. One of the most active groups is that trying to improve the outcomes for the children with disorders of sex development (DSD). Bulgaria is represented in one of the last initiatives (COST BM 1303) by the author of the third paper Dr Vilhelm Mladenov. In his short practical review he aims to present the indispensable for the modern diagnosis usage of Anti-Müllerian hormone (AMH). All current applications as well as promising new ones for the near future are accurately and comprehensively discussed. I am sure that regardless of the many papers on this topic, many readers will find the author's approach useful.

Last, but not least - the study of a team from the University Hospital in Pleven tells us about the prevalence of genital infections among children with type 1 diabetes mellitus who are badly controlled. Regardless of the efforts of the doctors, families, industry and different authorities, it is widely known that diabetes control during childhood is far from the desirable range. The very high number of children affected by genital infections, corresponding with higher HbAlc, is another reason to try to improve diabetes control. At the same time, the possibility of such infections should be taken into consideration while treating children with diabetes who have worse control (higher prevalence of hyperglycemia).

Enjoy reading!

Violeta Iotova, $\mathrm{MD}, \mathrm{PhD}, \mathrm{DSc}$

Professor in Paediatrics and Paediatric Endocrinology

Medical University of Varna, Bulgaria 